\title{
The spirit of capitalism and optimal capital taxation*
}

\author{
Fanghui $\mathrm{Li}^{\dagger}$ \\ Shandong University \\ Gaowang Wang ${ }^{\ddagger}$ \\ Shandong University \\ Heng-fu Zou ${ }^{\S}$ \\ Central University of Finance and Economics
}

May 20, 2020

\begin{abstract}
The paper reexamines the famous Chamley-Judd zero capital tax theorem in model economies where the agents are endowed with the spirit of capitalism. It is shown that the limiting capital income tax is not zero in general and depends on the utility specifications rather than the production technology. The similar formulas of optimal capital taxes are derived in more general settings with multiple physical capitals or heterogeneous agents (capitalists and workers).

Keywords: the Spirit of Capitalism; Capital Income Taxation; Heterogeneous Agents. JEL Classification Numbers: H21, E62.
\end{abstract}

\footnotetext{
${ }^{*}$ We would like to thank Liyan Yang, an anonymous referee, and Eric Young (associate editor) for their helpful comments and suggestions. Wang acknowedges the financial supports from Research Fund for Basic Theory (Project number: 2019jcyj001) provided by Shandong University of Development at Shandong University. All remaining errors are our responsibility.

${ }^{\dagger}$ Center for Economic Research, Shandong University, Jinan, China. E-mail: fanghui_li_05130163.com.

${ }^{\ddagger}$ Corresponding author. Center for Economic Research, Shandong University, Jinan, China. E-mail: gaowang. wang@sdu .edu.cn.

${ }^{\S}$ China Economics and Management Academy, Central University of Finance and Economics, Beijing, China. E-mail: hzoucema@gmail.com.
} 


\section{Introduction}

One of the most startling results in dynamic optimal tax theory is the Chamley (1986)-Judd (1985) zero capital income tax theorem. Although working in somewhat different settings, they draw the strikingly similar conclusions: capital should not be taxed in any steady state. The economic intuition is that the distorting taxes on the capital income depress the savings motives, decrease capital accumulation and do harm to economic growth. To eliminate these unpleasant distortions, capital should go untaxed in the long run. Their seminal works stimulate a large literature called the dynamic public finance: some authors confirm the theorem while others overturn it in different settings.

In this paper, we want to introduce the spirit of capitalism (or wealth effects or status preferences $)^{1}$ into the dynamic tax theory and reexamine optimal capital taxes. The reason why we incorporate the spirit of capitalism into the optimal tax theory is based on the following considerations. Firstly, taxing capital income means taxing the wealthy. The individuals with strong spirit of capitalism are probably the very wealth men in the society. The spirit-of-capitalism channel may have insightful implications for optimal tax theory. Secondly, some authors use the spirit-of-capitalism approach to change the modified goldenrule result in the optimal growth literature. They (Kurz, 1968; Zou, 1994, 1995) put forward a novel motive for savings and capital accumulation ${ }^{2}$, which may matter for taxing capital income. Thirdly, the spirit-of-capitalism approach has been used extensively in the literature to resolve many puzzles in economics and finance, such as the Equity Premiun Puzzle (EPP) (Bakshi and Chen, 1996; Smith, 2001; Boileau and Rebecca, 2007), savings and wealth accumulation (Cole, Mailath and Postlewaite, 1992; Zou, 1995), occupational choice (Doepke and Zilibotti, 2008), wealth distribution (Luo and Young, 2009), business cycle (Boileau and Rebecca, 2007; Karnizova, 2010), and cross-country growth differences (Kurz, 1968; Zou, 1994). In this paper, we want to examine whether and how the spirit of capitalism affects optimal capital taxes in the long run. The main conclusions drawn in this paper overturn the Chamley-Judd results. It is shown that the limiting capital tax is not zero generally and its sign depends only on the specifications of the utility function rather than the production technology. Furthermore, the similar formulas of optimal capital taxes are derived in extended settings with multiple physical capitals or heterogeneous agents (capitalists and workers).

The remainder of the paper is organized as follows. In section 2, we analyze a Ramsey taxation model and examine optimal capital taxes in the setting with the spirit of capitalism. In section 3, we derive the similar results in the extended model with heterogeneous agents. The concluding remarks are presented in section 4 .

\footnotetext{
${ }^{1}$ The modeling strategy of putting capital/wealth into the utility function is called as the spirit of capitalism (Bakshi and Chen, 1996; Boileau and Braeu, 2007; Doepke and Zilibotti, 2008; Karnizova, 2010; Smith, 2001; Zou, 1994, 1995), social status/norms (Cole, Mailath and Postlewaite, 1992; Luo and Young, 2009), or wealth effects (Kurz, 1968).

${ }^{2}$ The standard Ramsey model establishes that the net marginal product of per capita capital is equal to the time preference rate (i.e., $f^{\prime}\left(k^{m g}\right)=\rho$ ), which is well known as the modified golden rule level of physical capital. Whereas Kurz (1968) and Zou (1994) argue that the spirit of capitalism decreases the marginal product of capital (i.e., $f^{\prime}\left(k^{*}\right)=\rho-U_{k} / U_{c}<\rho=f^{\prime}\left(k^{m g}\right)$ ) and hence increases the steady state level of physical capital (i.e., $\left.k^{*}>k^{m g}\right)$. Zou (1995) develops the spirit-of-capitalism approach to explain the savings behavior of the very wealthy.
} 


\section{The model}

\subsection{Model setup}

Consider a production economy with no uncertainty. An infinitely lived representative household likes consumption, leisure and capital streams $\left\{c_{t}, l_{t}, k_{t}\right\}_{t=0}^{\infty}$ that give higher values of

$$
\sum_{t=0}^{\infty} \beta^{t} u\left(c_{t}, l_{t}, k_{t}\right),
$$

where $\beta \in(0,1)$ is the time discount rate, $c_{t} \geq 0, l_{t} \geq 0$ and $k_{t} \geq 0$ are consumption, leisure and physical capital stock at time t, respectively, and $u_{i}>0, u_{i i}<0, u_{i j} \geq 0$, for $i, j \in\{c, l, k\}$ with $i \neq j .{ }^{3}$ The household is endowed with one unit of time per period that can be used for leisure $l_{t}$ and labor $n_{t}$ :

$$
l_{t}+n_{t}=1
$$

The single good is produced with labor $n_{t}$ and capital $k_{t}$. Output can be consumed by households, used by the government, or used to augment the capital stock. The resource constraint is

$$
c_{t}+g_{t}+k_{t+1}=F\left(k_{t}, n_{t}\right)+\left(1-\delta_{k}\right) k_{t},
$$

where $\delta_{k} \in(0,1)$ denotes the depreciation rate of capital and $\{g\}_{t=0}^{\infty}$ is an exogenous sequence of government purchases. We assume that a standard increasing and concave production function that exhibits constant return to scale. By Euler's theorem on homogeneous functions, linear homogeneity of $F$ implies $F\left(k_{t}, n_{t}\right)=F_{k}\left(k_{t}, n_{t}\right) k_{t}+F_{n}\left(k_{t}, n_{t}\right) n_{t}$.

Government. The government finances its stream of purchases $\left\{g_{t}\right\}_{t=0}^{\infty}$ by levying flatrate, time varying taxes on earnings from capital at rate $\tau_{t}^{k}$ and earnings from labor at rate $\tau_{t}^{n}$. The government can also trade one-period bonds ${ }^{4}$, sequential trading of which suffices to accomplish any intertemporal trade in a world without uncertainty. Let $b_{t}$ be government indebtedness to the private sector, denominated in time $t$-goods, maturing at the beginning of period $t$. The government's budget constraint is

$$
g_{t}=\tau_{t}^{k} r_{t} k_{t}+\tau_{t}^{n} w_{t} n_{t}+\frac{b_{t+1}}{R_{t}}-b_{t}
$$

where $r_{t}$ and $w_{t}$ are the market-determined rental rate of capital and the wage rate for labor, respectively, denominated in units of time $t$ goods, and $R_{t}$ is the gross rate of return on one-period bonds held from $t$ to $t+1$. Interest earnings on bonds are assumed to be tax exempt; this assumption is innocuous for bond exchanges between the government and the private sector. We assume that the government can commit fully and credibly to future tax rates and thus evade the issue of time-consistency raised in Kydland and Prescott (1977). ${ }^{5}$

\footnotetext{
${ }^{3} u_{i i}<0$ shows that the marginal utility of any commodity decreases in its own consumption, while $u_{i j}>0(i \neq j)$ displays that the marginal utility of one commodity increases in the consumption of any other commodity.

${ }^{4}$ One-period governmeng bond cannot be accumulated like the private capital. This is why we do not introduce government bond into the utility function of the representative consumer.

${ }^{5}$ Xie (1997) raise the time inconsistency problem in the Ramsey taxation problem.
} 
Households. A representative household chooses $\left\{c_{t}, l_{t}, k_{t+1}, b_{t+1}\right\}_{t=0}^{\infty}$ to maximizes expression (1) subject to the time allocation constraint (2) and the sequence of budget constraints

$$
c_{t}+k_{t+1}+\frac{b_{t+1}}{R_{t}}=\left(1-\tau_{t}^{k}\right) r_{t} k_{t}+\left(1-\tau_{t}^{n}\right) w_{t} n_{t}+\left(1-\delta_{k}\right) k_{t}+b_{t},
$$

for $t \geq 0$, given $k_{0}$ and $b_{0}$. Here, $b_{t}$ is the real value of one-period government bond holdings that mature at the beginning of period $t$, denominated in units of time $t$ consumption. Substituting (2) into (1) and forming the Lagrangian with the Lagrange multiplier $\lambda_{t}$, we derive the first order conditions w.r.t $c_{t}, n_{t}, k_{t+1}$ and $b_{t+1}$, respectively, ${ }^{6}$

$$
\begin{gathered}
u_{c}(t)=\lambda_{t}, t \geq 0, \\
u_{l}(t)=\lambda_{t}\left(1-\tau_{t}^{n}\right) w_{t}, t \geq 0, \\
\lambda_{t}=\beta\left\{u_{k}(t+1)+\lambda_{t+1}\left[\left(1-\tau_{t+1}^{k}\right) r_{t+1}+1-\delta_{k}\right]\right\}, t \geq 0, \\
\frac{\lambda_{t}}{R_{t}}=\beta \lambda_{t+1}, t \geq 0 .
\end{gathered}
$$

From equations (6) and (7), we have

$$
\frac{u_{l}(t)}{u_{c}(t)}=\left(1-\tau_{t}^{n}\right) w_{t},
$$

which displays that the marginal rate of substitution of consumption and leisure equals their (after-tax) price ratio. Combining equations (6) and (8) yields us the consumption Euler equation

$$
u_{c}(t)=\beta\left\{u_{k}(t+1)+u_{c}(t+1)\left[\left(1-\tau_{t+1}^{k}\right) r_{t+1}+1-\delta_{k}\right]\right\},
$$

in which the demand for status $\left(u_{k}>0\right)$ is a new channel for savings. ${ }^{7}$ Putting equation (9) into (8) leads to the modified no-arbitrage condition

$$
R_{t}=\frac{\left(1-\tau_{t+1}^{k}\right) r_{t+1}+1-\delta_{k}}{\left[1-\beta \frac{u_{k}(t+1)}{u_{c}(t)}\right]},
$$

where a new positive term $\beta \frac{u_{k}(t+1)}{u_{c}(t)}$ is present in the denominator.

Firms. In each period, by taking $\left(r_{t}, w_{t}\right)$ as given, the representative firm rents capital and labor from households and maximizes its profits, i.e., $F\left(k_{t}, n_{t}\right)-r_{t} k_{t}-w_{t} n_{t}$. The first order conditions for this problem are

$$
r_{t}=F_{k}\left(k_{t}, n_{t}\right), w_{t}=F_{n}\left(k_{t}, n_{t}\right) .
$$

In words, inputs should be employed until the marginal product of the last unit is equal to its rental price. With constant return to scale, we get the standard result that pure profits are zero.

\footnotetext{
${ }^{6}$ Let $u_{c}(t)$ and $u_{l}(t)$ denote the time $t$ values of the derivatives of $u\left(c_{t}, l_{t}\right)$ with respect to consumption and leisure, respectively.

${ }^{7}$ This new savings motive can be seen more clearly from the steady state version of equation (11) without taxes, namely, $F_{k}=1 / \beta-1+\delta_{k}-u_{k} / u_{c}$. The marginal product of capital is $F_{k}$ lower than the one in the standard model without the spirit of captalism, due to a new positive term $u_{k} / u_{c}(>0)$ here.
} 


\subsection{Primal approach to the Ramsey problem}

We examine the optimal taxes in the long run by utilizing the Primal approach developed by Atkinson and Stiglitz (1980) and Lucas and Stokey (1983). For this purpose we present the following useful definitions.

Definition 2.1 A competive equilibrium is an allocation $\left\{c_{t}, l_{t}, n_{t}, k_{t+1}, b_{t+1}\right\}_{t=0}^{\infty}$, a price system $\left\{w_{t}, r_{t}, R_{t}\right\}_{t=0}^{\infty}$, and government policies $\left\{g_{t}, \tau_{t}^{k}, \tau_{t}^{n}, B_{t+1}\right\}_{t=0}^{\infty}$ such that (a) given the price system and the government poicy, the allocation solves both the firm's problem and the household's problem with $b_{t}=B_{t}$ for all $t \geq 0$; (b) given the allocation and the price system, the government policy satisfies the sequence of government budget constraint (4) for all $t \geq 0$; (3) the time allocation constraint (2) and the resource constraint (3) are satisfied for all $t \geq 0$.

There are many competitive equilibria, indexed by different government policies. And this multiplicity motivates the Ramsey problem.

Definition 2.2 Given $k_{0}, b_{0}$ and $\tau_{0}^{k}$, the Ramsey problem is to choose a competitive equilibrium that maximizes expression (1).

Firstly, we derive the following implementability condition ${ }^{8}$

$$
\sum_{t=0}^{\infty} \beta^{t}\left[u_{c}(t) c_{t}-u_{l}(t) n_{t}+u_{k}(t) k_{t}\right]=u_{c}(0)\left\{\left[\left(1-\tau_{0}^{k}\right) r_{0}+1-\delta_{k}\right] k_{0}+b_{0}\right\}+u_{k}(0) k_{0} \equiv \widetilde{A}_{1}
$$

Then, the Ramsey problem is to maximize expression (1) subject to equation (14) and the resource constraint (3). We proceed by assuming that government expenditures are small enough that the problem has a convex constraint set and that we can approach it using Lagrangian methods. In particular, let $\Phi$ be the Lagrangian multiplier on equation (14) and define

$$
U(t) \equiv U\left(c_{t}, n_{t}, k_{t}, \Phi\right) \equiv u\left(c_{t}, 1-n_{t}, k_{t}\right)+\Phi\left[u_{c}(t) c_{t}-u_{l}(t) n_{t}+u_{k}(t) k_{t}\right]
$$

Then we can construct the Lagrangian

$$
J=\sum_{t=0}^{\infty} \beta^{t}\left\{U(t)+\theta_{t}\left[F\left(k_{t}, n_{t}\right)-c_{t}-g_{t}-k_{t+1}+\left(1-\delta_{k}\right) k_{t}\right]\right\}-\Phi \widetilde{A}_{1},
$$

where $\left\{\theta_{t}\right\}_{t=0}^{\infty}$ is a sequence of Lagrangian multipliers. The first order conditions for this problem are

$$
\begin{gathered}
c_{t}: \quad U_{c}(t)=\theta_{t}, t \geq 1 \\
k_{t+1}: \quad \theta_{t}=\beta\left\{U_{k}(t+1)+\theta_{t+1}\left[F_{k}(t+1)+1-\delta_{k}\right]\right\}, t \geq 0 \\
n_{t}: \quad-U_{n}(t)=\theta_{t} F_{n}(t), t \geq 1
\end{gathered}
$$

\footnotetext{
${ }^{8}$ The derivation of the implementability condition is placed in appendix A.
} 
where

$$
\begin{aligned}
U_{c}(t) & =u_{c}(t)+\Phi\left[u_{c c}(t) c_{t}+u_{c}(t)-u_{l c}(t) n_{t}+u_{k c}(t) k_{t}\right], \\
U_{n}(t) & =-u_{l}(t)+\Phi\left[-u_{c l}(t) c_{t}+u_{l l}(t) n_{t}-u_{l}(t)-u_{l k}(t) k_{t}\right], \\
U_{k}(t+1) & =u_{k}(t+1)+\Phi\left[u_{c k}(t+1) c_{t+1}-u_{l k}(t+1) n_{t+1}+u_{k k}(t+1) k_{t+1}+u_{k}(t+1)\right] .
\end{aligned}
$$

Consider the special case in which there is a $T \geq 0$ for which $g_{t}=g$ for all $t \geq T$. Assume that there exists a solution to the Ramsey problem and that it converges to a time-invariant allocation, so that $c, n$ and $k$ are constant after some time. Then we have the following

Proposition 2.1 Suppose the economy converges to an interior steady state in the dynamic taxation model with the spirit of capitalism. 9 The optimal capital income tax is positive, zero, or negative, if and only if $\left(u_{k} \eta_{1}-u_{c} \eta_{3}\right)$ is larger than, equal to, or less than zero. Namely,

$$
\begin{aligned}
\tau^{k}=0 \Longleftrightarrow\left(u_{k} \eta_{1}-u_{c} \eta_{2}\right) & >0, \\
& < \\
& <
\end{aligned}
$$

where

$$
\eta_{1}=u_{c c} c-u_{l c} n+u_{k c} k, \eta_{2}=u_{c k} c-u_{l k} n+u_{k k} k .
$$

Proof The proof is placed in online Appendix A.

Proposition 2.1 tells that the limiting capital income tax is in general not zero, since the term $\left(u_{k} \eta_{1}-u_{c} \eta_{2}\right)$ is generally not equal to zero. It should be noted that the sign of the optimal capital tax rate relies only on the specification of the utility function rather than the production technology. That is, if the consumer cares about the utility from both social status and consumption, then the zero capital income taxation theorem will not hold. If there is no status concern (i.e., $u_{k}=0$ ), then the limiting capital income tax is zero (i.e., $\tau^{k}=0$ ), and the corresponding labor income tax is nonnegative (i.e., $\tau^{n} \geq 0$ ), ${ }^{10}$ which corresponds to the zero capital income taxation developed by Chamley (1986).

For this general utility function, the expression of the term $\left(u_{k} \eta_{1}-u_{c} \eta_{2}\right)$ is very complicated and hard to develop the intuitions. For this purpose, we assume the instantaneous utility function of the representative consumer is of an additively separable version, namely,

$$
u(c, l, k)=\alpha_{c} u(c)+\alpha_{n} v(1-n)+\alpha_{k} w(k), \alpha_{i}>0, i \in\{c, n, k\} .
$$

Then we know that $u^{\prime}>0, u^{\prime \prime}<0, v^{\prime}>0, v^{\prime \prime}<0, w^{\prime}>0$, and $w^{\prime \prime}<0$, due to the assumed properties of $u(c, l, k)$. Then we have

\footnotetext{
${ }^{9}$ Different from the standard Ramsey model, we now cannot prove the existence and uniqueness of the steady state. In our model, the steady state version of the consumption Euler equation is $1 / \beta=u_{k} / u_{c}+$ $\left[\left(1-\tau^{k}\right) F_{k}+1-\delta_{k}\right]$. The new term $u_{k} / u_{c}$ prevents us from solving the steady state easily and brings about the possibility of multiple equilibria, as Kurz (1968) had already talked about this. For this reason, our paper assumes the existence of a steady state and focuses on the taxation problem.

${ }^{10}$ Notice that, if $u_{k}=0$, then the term $u_{k} \eta_{1}-u_{c} \eta_{3}=0$, implying $\tau^{k}=0$; meanwhile, $\tau^{n}=$ $\frac{1}{u_{c} F_{n}} \frac{\Phi}{1+\Phi}\left[\left(u_{c l}-F_{n} u_{c c}\right) c+\left(-u_{l l}+F_{n} u_{l c}\right) n\right] \geq 0$, due to $u_{c}>0, F_{n}>0, u_{c l} \geq 0, u_{c c}<0, u_{l l}<0$ and $u_{l c} \geq 0$.
} 
Proposition 2.2 Assume that the utility function of the representative consumer takes the additively separable version in (19). The optimal capital income tax is positive, zero, or negative, if and only if the capital elasticity of marginal utility of capital is less than, equal to, or larger than the consumption elasticity of marginal utility of consumption. Namely,

$$
\begin{aligned}
& > \\
\tau^{k} & =0 \Longleftrightarrow \frac{w^{\prime \prime}(k) k}{w^{\prime}(k)} \\
& <
\end{aligned}=\frac{u^{\prime \prime}(c) c}{u^{\prime}(c)} .
$$

Proof Putting the additively separable utility function in (18) yields us the results. $\square$

Proposition 2.1 shows that optimal taxes depend on the relative values of the marginal utility elasticities for different utility goods (consumption goods and capital goods). If the marginal utility of capital responses more sensitively to one percent change of capital stock, compared to the response of the marginal utility of consumption to one percent change of consumption, then the optimal capital tax will be positive; if not, the optimal capital tax will be negative. However, if they (consumption and capital goods) have the same sensitivity, then the optimal capital tax will be zero.

Roughly speaking, we may also develop the following intuitions. If we look down upon these marginal utilities as their shadow prices, namely, $u_{i}(c, l, k)=\lambda_{i}, i \in\{c, l, k\}$, then we will be able to define the price elasticities of demand for them, namely, $\epsilon_{i} \equiv-\frac{\partial i}{\partial \lambda_{i}} \frac{\lambda_{i}}{i}, i \in$ $\{c, l, k\}$. Simple calculations gives rise to $\epsilon_{c}=-u^{\prime}(c) / u^{\prime \prime}(c) c, \epsilon_{n}=-v^{\prime}(1-n) / v^{\prime \prime}(1-n) n$, and $\epsilon_{k}=-w^{\prime}(k) / w^{\prime \prime}(k) k$. Thus if the price elasticity of demand for capital is less than that for consumption, then the optimal capital income tax will be positive; conversely, if the price elasticity of demand for capital is larger than that for consumption, then the optimal capital income tax will be negative. In the latter case, the government provides subsidies for the larger welfare loss of the high substitution effect driven by price changes.

To explore how the spirit of capitalism affects the optimal capital taxes, we will extend the baseline model to include two types of physical capitals: one, $k_{t}$, with interest rate $r_{t}$ and depreciation rate $\delta_{k}$, enters the utility, and the other, $\kappa_{t}$, with interest rate $r_{t}^{\kappa}$ depreciation rate $\delta_{\kappa}$, does not enter the utility function. We also assume that the production function of the economy, $F\left(k_{t}, \kappa_{t}, n_{t}\right)$, is linearly homogenous on three production factors $\left(k_{t}, \kappa_{t}, n_{t}\right)$. It is shown in Proposition 2.3 that the limiting tax rate on $r_{t}$ of physical capital with status concerns is indefinite and the one on $r_{t}^{\kappa}$ of other physical capitals without status concerns is zero.

Proposition 2.3 (Two Types of Physical Capitals) If the steady state exists in the extended model with two types of physical capitals, then the limiting tax on capital with status concerns is indefinite and pinned down by equation (18), the limiting tax on capital without status concerns equals zero. ${ }^{11}$

\footnotetext{
${ }^{11}$ In the taxation equations with two types of physical capital, all of the partial derivatives depend on $\kappa$, namely, $F_{i}=F_{i}(k, \kappa, n), i \in\{k, \kappa, n\}$. The proof of Proposition 2.3 is similar to the proof of Proposition 1 and omitted here, which is available upon request.
} 


\section{$3 \quad$ Heterogeneous agents}

In this section we extend the model to more realistic settings with heterogeneous agents and also show that the limiting capital income tax is not zero generally. Each agent is a point in the unit interval $[0,1]$. There are two types of agents, capitalists/entrepreneurs and workers, with exogenously given weights $\alpha$ and $1-\alpha$, respectively. Endowed with the spirit of capitalism, entrepreneurs save and trade with the government. But they do not work. Workers work for salaries and derive utility from consumption and leisure. We use superscripts 1 and 2 to denote capitalists and workers respectively. Both capitalists and workers discount the future with a common discount factor $\beta \in(0,1)$. Firms hire labor from workers, rent capital from capitalists and produce the final goods with the linearly homogenous production technology $F\left(k_{t}^{1}, n_{t}^{2}\right)$.

The representative capitalist solves the following maximization problem:

$$
\max _{\left\{c_{t}^{1}, k_{t+1}^{1}, b_{t+1}^{1}\right\}_{t=0}^{\infty}} \sum_{t=0}^{\infty} \beta^{t} u^{1}\left(c_{t}^{1}, k_{t}^{1}\right), \text { s.t. } c_{t}^{1}+k_{t+1}^{1}-(1-\delta) k_{t}^{1}=\left(1-\tau_{t}^{k}\right) r_{t} k_{t}^{1}+b_{t}-\frac{b_{t+1}}{R_{t}},
$$

and the representative worker solves

$$
\max _{\left\{c_{t}^{2}, n_{t}^{2}\right\}_{t=0}^{\infty}} \sum_{t=0}^{\infty} \beta^{t} u^{2}\left(c_{t}^{2}, 1-n_{t}^{2}\right), \text { s.t., } c_{t}^{2}=\left(1-\tau_{t}^{n}\right) w_{t} n_{t}^{2}
$$

The government finances its expenditures $\left\{g_{t}\right\}_{t=0}^{\infty}$ with tax revenues and one-period bonds and runs a balanced budget

$$
g_{t}=\tau_{t}^{k} r_{t} k_{t}^{1}+\tau_{t}^{n} w_{t} n_{t}^{2}+\frac{b_{t+1}}{R_{t}}-b_{t}
$$

The resource constraint of the economy is

$$
c_{t}^{1}+c_{t}^{2}+k_{t+1}^{1}-(1-\delta) k_{t}^{1}+g_{t}=F\left(k_{t}^{1}, n_{t}^{2}\right) .
$$

From the first order conditions for the representative capitalist, we have the consumption Euler equation

$$
u_{c}^{1}(t)=\beta\left\{u_{k}^{1}(t+1)+u_{c}^{1}(t+1)\left[\left(1-\tau_{t+1}^{k}\right) r_{t+1}+(1-\delta)\right]\right\},
$$

and the no-arbitrage condition

$$
R_{t}=\frac{\left(1-\tau_{t+1}^{k}\right) r_{t+1}+1-\delta}{1-\beta u_{k}^{1}(t+1) / u_{c}^{1}(t)}
$$

The optimization of the representative worker is described by the static equation

$$
\frac{u_{l}^{2}\left(c_{t}^{2}, 1-n_{t}^{2}\right)}{u_{c}^{2}\left(c_{t}^{2}, 1-n_{t}^{2}\right)}=\left(1-\tau_{t}^{n}\right) w_{t}=\frac{c_{t}^{2}}{n_{t}^{2}} .
$$

The implementability condition can be derived as follows

$$
\sum_{t=0}^{\infty} \beta^{t}\left[u_{c}^{1}(t) c_{t}^{1}+u_{k}^{1}(t) k_{t}^{1}\right]=u_{c}^{1}(0)\left\{\left[\left(1-\tau_{0}^{k}\right) r_{0}+1-\delta\right] k_{0}^{1}+b_{0}\right\}+u_{k}^{1}(0) k_{0}^{1} \equiv \widetilde{A}_{2} .
$$


The Ramsey problem is to maximize a weighted sum of utilities with weights $\alpha$ on capitalists and $(1-\alpha)$ on workers

$$
\max _{\left\{c_{t}^{1}, c_{t}^{2}, k_{t+1}^{1}, n_{t}^{2}\right\}} \sum_{t=0}^{\infty} \beta^{t}\left[\alpha u^{1}\left(c_{t}^{1}, k_{t}^{1}\right)+(1-\alpha) u^{2}\left(c_{t}^{2}, 1-n_{t}^{2}\right)\right],
$$

subject to the implementability condition (23), the static optimization condition of the worker (22), i.e., $u_{c}^{2}(t) c_{t}^{2}=u_{l}^{2}(t) n_{t}^{2}$, and the resource constraint (20).

Solving the Ramsey problem and comparing the optimality conditions with the individual's problem lead to the following

Proposition 3.1 Assume that there exists an interior steady state in the economy with heterogeneous agents. The optimal capital income tax is positive, zero, or negative, if and only if $\left(u_{k}^{1} \varrho_{1}-u_{c}^{1} \varrho_{2}\right)$ is larger than, equal to, or less than zero, namely,

$$
\begin{aligned}
\tau^{k} & >0 \Longleftrightarrow\left(u_{k}^{1} \varrho_{1}-u_{c}^{1} \varrho_{2}\right) \\
& =0 \\
& <
\end{aligned}
$$

where

$$
\varrho_{1} \equiv\left[u_{c c}^{1}(t) c_{t}^{1}+u_{k c}^{1}(t) k_{t}^{1}\right], \varrho_{2} \equiv\left[u_{k k}^{1}(t+1) k_{t+1}^{1}+u_{c k}^{1}(t+1) c_{t+1}^{1}\right] .
$$

Proof The proof is put in online Appendix B.

Proposition 3.2 Assume that the utility function of the representative consumer takes the additively separable functions, namely, $u^{1}\left(c_{t}^{1}, k_{t}^{1}\right)=\alpha_{c} u^{1}\left(c_{t}^{1}\right)+\alpha_{k} w\left(k_{t}^{1}\right)$, and $u^{2}\left(c_{t}^{2}, 1-\right.$ $\left.n_{t}^{2}\right)=\alpha_{c} u^{2}\left(c_{t}^{2}\right)+\alpha_{n} w\left(1-n_{t}^{2}\right)$. Then the optimal taxes are determined by

$$
\begin{aligned}
\tau^{k} & >0 \Longleftrightarrow \frac{w^{1 \prime \prime}\left(k^{1}\right) k^{1}}{w^{1 \prime}\left(k^{1}\right)}=\frac{u^{1 \prime \prime}\left(c^{1}\right) c^{1}}{u^{1 \prime}\left(c^{1}\right)} .
\end{aligned}
$$

Proposition 4.1 and Proposition 4.2 show that in the more realistic setting with heterogeneous agents, we draw very similar conclusion for the optimal capital income taxation: zero capital income taxation theorem does not hold generally, and the optimal capital income tax depends on the particular forms of the utility function and closely related to the associated elasiticities. The intuitions are also similar to the baseline model.

\section{Conclusion}

We reexamine the Chamley-Judd zero optimal capital income taxation theorem in the new settings populated with agents endowed with spirit of capitalism. We find that the limiting capital income tax is not zero generally and depends only on the specification of the utility function but not on the production side of the economy. Furthermore, the similar formulas of optimal capital taxes are derived in extended settings with multiple physical capitals or with heterogeneous agents (capitalists and workers). This research puts forward a new channel to overturn the Chamley-Judd theorem. 


\section{Online appendix (not for publication)}

\subsection{Appendix A: Proof of Proposition 2.1}

Proof of Proposition 2.1. We first derive the implementability condition. Define the ArrowDebreu price $q_{t}^{0} \equiv \sum_{i=0}^{t-1} R_{i}^{-1}$ for $t \geq 1$, with the numeraire $q_{0}^{0}=1$. From the consumer's first order conditions $u_{c}(t)=\lambda_{t}$ and $\frac{\lambda_{t}}{R_{t}}=\beta \lambda_{t+1}$, we have

$$
q_{t}^{0}=\beta^{t} \frac{u_{c}(t)}{u_{c}(0)}
$$

Iterating the household's flow budget constraint from the time 0 , we obtain the present-value budget constraint that

$$
b_{0}=\sum_{t=0}^{\infty} q_{t}^{0}\{c_{t}-\left(1-\tau_{t}^{n}\right) w_{t} n_{t}+\underbrace{k_{t+1}-\left[\left(1-\tau_{t}^{k}\right) r_{t}+1-\delta\right] k_{t}}_{\equiv x_{t}}\}+\lim _{T \rightarrow \infty} q_{t}^{0} b_{T} .
$$

The term $\sum_{t=0}^{\infty} q_{t}^{0} x_{t}$ in (26) is derived as

$$
\begin{aligned}
& \sum_{t=0}^{\infty} q_{t}^{0} x_{t} \\
& =\sum_{t=0}^{\infty} q_{t}^{0}\left\{k_{t+1}-\left[\left(1-\tau_{t}^{k}\right) r_{t}+1-\delta\right] k_{t}\right\} \\
& =\lim _{T \rightarrow \infty} \sum_{t=0}^{T} q_{t}^{0}\left\{k_{t+1}-\left[\left(1-\tau_{t}^{k}\right) r_{t}+1-\delta\right] k_{t}\right\} \\
& =\lim _{T \rightarrow \infty}\left\{\sum_{t=0}^{T} q_{t}^{0} k_{t+1}-\sum_{t=1}^{T} q_{t}^{0}\left[\left(1-\tau_{t}^{k}\right) r_{t}+1-\delta\right] k_{t}\right\}-\left[\left(1-\tau_{0}^{k}\right) r_{0}+1-\delta\right] k_{0} \\
& =\lim _{T \rightarrow \infty} \sum_{t=0}^{T-1}\left\{q_{t}^{0}-q_{t+1}^{0}\left[\left(1-\tau_{t+1}^{k}\right) r_{t+1}+1-\delta\right]\right\} k_{t+1}-\left[\left(1-\tau_{0}^{k}\right) r_{0}+1-\delta\right] k_{0}+\lim _{T \rightarrow \infty} q_{T}^{0} k_{T+1} \\
& =\sum_{t=0}^{\infty}\left\{q_{t}^{0}-q_{t+1}^{0}\left[\left(1-\tau_{t+1}^{k}\right) r_{t+1}+1-\delta\right]\right\} k_{t+1}-\left[\left(1-\tau_{0}^{k}\right) r_{0}+1-\delta\right] k_{0}+\lim _{T \rightarrow \infty} q_{T}^{0} k_{T+1} .
\end{aligned}
$$

Substituting $u_{c}(t)=\lambda_{t}$ and $\frac{\lambda_{t}}{R_{t}}=\beta \lambda_{t+1}$ in the modified no-arbitrage condition leads to:

$$
R_{t}-\left[\left(1-\tau_{t+1}^{k}\right) r_{t+1}+1-\delta_{k}\right]=\frac{u_{k}(t+1)}{u_{c}(t+1)}
$$

Multiplying both sides of (28) with $q_{t+1}^{0}$ and using the definition of the Arrow-Debreu price, we have

$$
q_{t}^{0}-q_{t+1}^{0}\left[\left(1-\tau_{t+1}^{k}\right) r_{t+1}+1-\delta_{k}\right]=q_{t+1}^{0} \frac{u_{k}(t+1)}{u_{c}(t+1)} .
$$


Plugging (29) in the term (27) gives rise to

$$
\sum_{t=0}^{\infty} q_{t}^{0} x_{t}=\sum_{t=0}^{\infty} q_{t+1}^{0} \frac{u_{k}(t+1)}{u_{c}(t+1)} k_{t+1}-\left[\left(1-\tau_{0}^{k}\right) r_{0}+1-\delta\right] k_{0}+\lim _{T \rightarrow \infty} q_{T}^{0} k_{T+1} .
$$

Substituting (30) into equation (26) and imposing the following two transversality conditions

$$
\lim _{T \rightarrow \infty} q_{t}^{0} b_{T}=0, \lim _{T \rightarrow \infty} q_{T}^{0} k_{T+1}=0,
$$

we obtain the present-value budget constraint of the representative consumer

$$
\sum_{t=0}^{\infty}\left[q_{t}^{0} c_{t}+q_{t+1}^{0} \frac{u_{k}(t+1)}{u_{c}(t+1)} k_{t+1}\right]=\sum_{t=0}^{\infty} q_{t}^{0}\left(1-\tau_{t}^{n}\right) w_{t} n_{t}+\left[\left(1-\tau_{0}^{k}\right) r_{0}+1-\delta\right] k_{0}+b_{0} .
$$

Substituting the price equations $(25)$ and $\frac{u_{l}(t)}{u_{c}(t)}=\left(1-\tau_{t}^{n}\right) w_{t}$ into (31) and rearranging, we have the implementability condition:

$$
\sum_{t=0}^{\infty} \beta^{t}\left[u_{c}(t) c_{t}-u_{l}(t) n_{t}+u_{k}(t) k_{t}\right]=u_{c}(0)\left\{\left[\left(1-\tau_{0}^{k}\right) r_{0}+1-\delta_{k}\right] k_{0}+b_{0}\right\}+u_{k}(0) k_{0} \equiv \widetilde{A}_{1}
$$

Secondly, to solve the Ramsey problem, we form the Lagrangian

$$
J=\sum_{t=0}^{\infty} \beta^{t}\left\{U(t)+\theta_{t}\left[F\left(k_{t}, n_{t}\right)-c_{t}-g_{t}-k_{t+1}+\left(1-\delta_{k}\right) k_{t}\right]\right\}-\Phi \widetilde{A}_{1} .
$$

Note that

$$
U(t) \equiv U\left(c_{t}, n_{t}, k_{t}, \Phi\right) \equiv u\left(c_{t}, 1-n_{t}, k_{t}\right)+\Phi\left[u_{c}(t) c_{t}-u_{l}(t) n_{t}+u_{k}(t) k_{t}\right],
$$

where $\Phi$ is the Lagrangian multiplier w.r.t the IMC and $\left\{\theta_{t}\right\}_{t=0}^{\infty}$ is a sequence of Lagrangian multipliers. The first order conditions are

$$
\begin{gathered}
c_{t}: \quad U_{c}(t)=\theta_{t}, t \geq 1 \\
k_{t+1}: \quad \theta_{t}=\beta\left\{U_{k}(t+1)+\theta_{t+1}\left[F_{k}(t+1)+1-\delta_{k}\right]\right\}, t \geq 0 \\
n_{t}: \quad-U_{n}(t)=\theta_{t} F_{n}(t), t \geq 1
\end{gathered}
$$

where

$$
\begin{aligned}
U_{c}(t) & =u_{c}(t)+\Phi\left[u_{c c}(t) c_{t}+u_{c}(t)-u_{l c}(t) n_{t}+u_{k c}(t) k_{t}\right], \\
U_{n}(t) & =-u_{l}(t)+\Phi\left[-u_{c l}(t) c_{t}+u_{l l}(t) n_{t}-u_{l}(t)-u_{l k}(t) k_{t}\right], \\
U_{k}(t+1) & =u_{k}(t+1)+\Phi\left[u_{c k}(t+1) c_{t+1}-u_{l k}(t+1) n_{t+1}+u_{k k}(t+1) k_{t+1}+u_{k}(t+1)\right] .
\end{aligned}
$$

Finally, we examine the steady state of the economy. The steady state versions for equations (33)-(35) are

$$
\theta=(1+\Phi) u_{c}+\Phi \underbrace{\left(u_{c c} c-u_{l c} n+u_{k c} k\right)}_{\equiv \eta_{1}},
$$




$$
\begin{gathered}
\theta\left[1-\beta\left(F_{k}+1-\delta_{k}\right)\right]=\beta\left[(1+\Phi) u_{k}+\Phi(\underbrace{u_{c k} c-u_{l k} n+u_{k k} k}_{\equiv \eta_{2}})\right] \\
\theta F_{n}=(1+\Phi) u_{l}+\Phi \underbrace{\left(u_{c l} c-u_{l l} n+u_{k l} k\right)}_{\equiv \eta_{3}} .
\end{gathered}
$$

From equations (36) and (38), we solve for $\frac{(1+\Phi)}{\theta}$ and $\frac{\Phi}{\theta}$ as follows:

$$
\frac{(1+\Phi)}{\theta}=\frac{\eta_{3}-F_{n} \eta_{1}}{u_{c} \eta_{3}-u_{l} \eta_{1}}, \frac{\Phi}{\theta}=\frac{u_{c} F_{n}-u_{l}}{u_{c} \eta_{3}-u_{l} \eta_{1}} .
$$

From the consumption Euler equation, we know that

$$
F_{k}+1-\delta_{k}=\frac{1}{\beta}-\frac{u_{k}}{u_{c}}+\tau^{k} F_{k} .
$$

Dividing both sides of (37) by $\theta$ and plugging (39) and (40) into it, we obtain

$$
\tau^{k}=\frac{1}{u_{c} F_{k}} \underbrace{\frac{\left(u_{c} F_{n}-u_{l}\right)}{\left(u_{c} \eta_{3}-u_{l} \eta_{1}\right)}}_{=\frac{\Phi}{\theta}}\left(u_{k} \eta_{1}-u_{c} \eta_{2}\right) .
$$

From equation $(39)$, the term $\left(u_{c} F_{n}-u_{l}\right) /\left(u_{c} \eta_{3}-u_{l} \eta_{1}\right)=\frac{\Phi}{\theta}$ is nonnegative, because the Lagrange multiplier $\Phi$ is nonnegative, while the insatiable utility function implies that $\theta$ is strictly positive. Notice that $u_{c}$ and $F_{k}$ are both strictly positive. Hence the sign of the limiting capital income tax is determined completely by the sign of the term $\left(u_{k} \eta_{1}-u_{c} \eta_{2}\right)$. To examine the optimal labor income tax, we combine (36) with (38), rearrange the terms, and obtain

$$
u_{c} F_{n}-u_{l}=\frac{\Phi}{1+\Phi}\left(\eta_{3}-F_{n} \eta_{1}\right) .
$$

Substituting the marginal productivity condition of the firm into $\frac{u_{l}(t)}{u_{c}(t)}=\left(1-\tau_{t}^{n}\right) w_{t}$ gives us

$$
u_{c} F_{n}-u_{l}=\tau^{n} u_{c} F_{n}
$$

Combining (42) with (43) leads to

$$
\tau^{n}=\frac{1}{u_{c} F_{n}} \frac{\Phi}{1+\Phi}\left(\eta_{3}-F_{n} \eta_{1}\right)
$$

Since $u_{c}>0, F_{n}>0$ and the multiplier $\Phi$ is nonnegative, the limiting optimal labor income tax depends on the value of the term in the bracket, listed in the theorem. $\square$ 


\subsection{Appendix B: Proof of Proposition 3.1}

Proof of Proposition 3.1. To solve the Ramsey problem, we construct the Lagrangian

$$
\begin{aligned}
L & =\sum_{t=0}^{\infty} \beta^{t}\left[\alpha u^{1}\left(c_{t}^{1}, k_{t}^{1}\right)+(1-\alpha) u^{2}\left(c_{t}^{2}, 1-n_{t}^{2}\right)\right]+\widehat{\Phi}\left[\sum_{t=0}^{\infty} \beta^{t}\left[u_{c}^{1}(t) c_{t}^{1}+u_{k}^{1}(t) k_{t}^{1}\right]-\widetilde{A}_{2}\right] \\
& +\sum_{t=0}^{\infty} \beta^{t} \mu_{t}\left[u_{l}^{2}(t) n_{t}^{2}-u_{c}^{2}(t) c_{t}^{2}\right]+\sum_{t=0}^{\infty} \beta^{t} \theta_{t}\left[F\left(k_{t}^{1}, n_{t}^{2}\right)-c_{t}^{1}-c_{t}^{2}-k_{t+1}^{1}+(1-\delta) k_{t}^{1}-g_{t}\right],
\end{aligned}
$$

where $\widehat{\Phi},\left\{\mu_{t}\right\}_{t=0}^{\infty}$ and $\left\{\theta_{t}\right\}_{t=0}^{\infty}$ are the Lagrange multipliers associated with the implementability condition, the optimality condition of the worker, and the resource constraint, respectively. The optimality conditions w.r.t $c_{t}^{1}, k_{t+1}^{1}, c_{t}^{2}$, and $n_{t}^{2}$ are:

$$
\begin{aligned}
& (\alpha+\widehat{\Phi}) u_{c}^{1}(t)+\widehat{\Phi} \underbrace{\left[u_{c c}^{1}(t) c_{t}^{1}+u_{k c}^{1}(t) k_{t}^{1}\right]}_{\equiv \varrho_{1}}=\theta_{t}, t \geq 1, \\
& \beta\{(\alpha+\widehat{\Phi}) u_{k}^{1}(t+1)+\widehat{\Phi} \underbrace{\left[u_{k k}^{1}(t+1) k_{t+1}^{1}+u_{c k}^{1}(t+1) c_{t+1}^{1}\right]}_{\equiv \varrho_{2}}\}=\theta_{t}-\beta \theta_{t+1}\left[F_{k}(t+1)+1-\delta\right], t \geq 0 \\
& \left(1-\alpha-\mu_{t}\right) u_{c}^{2}(t)+\mu_{t} \underbrace{\left[u_{l c}^{2}(t) n_{t}^{2}-u_{c c}^{2}(t) c_{t}^{2}\right]}_{\equiv \varrho_{3}}=\theta_{t}, t \geq 0, \\
& \left(1-\alpha-\mu_{t}\right) u_{l}^{2}(t)+\mu_{t} \underbrace{\left[u_{l l}^{2}(t) n_{t}^{2}-u_{c l}^{2}(t) c_{t}^{2}\right]}_{\equiv \varrho 4}=\theta_{t} F_{n}(t), t \geq 0 .
\end{aligned}
$$

Suppose that the economy converges to an interior steady state. Combining the steady state equations of the consumption Euler equation of the capitalist and (46) yields us

$$
\tau^{k}=\frac{1}{F_{k}}\left[\frac{u_{k}^{1}}{u_{c}^{1}}-\frac{\alpha+\widehat{\Phi}}{\theta} u_{k}^{1}-\frac{\widehat{\Phi}}{\theta} \varrho_{2}\right] .
$$

Solving equation (45) for $(\alpha+\widehat{\Phi}) / \theta=\left(1-\widehat{\Phi} \varrho_{1} / \theta\right) / u_{c}^{1}$ and putting it into (49), we solve for

$$
\tau^{k}=\frac{\widehat{\Phi}}{\theta} \frac{1}{u_{c}^{1} F_{k}}\left(u_{k}^{1} \varrho_{1}-u_{c}^{1} \varrho_{2}\right) .
$$

To search for the limiting labor income tax, we combine equations (47) and (48) to derive

$$
\frac{u_{l}^{2}}{u_{c}^{2}}=\frac{\left(\theta F_{n}-\mu \varrho_{3}\right)}{\left(\theta-\mu \varrho_{2}\right)} .
$$

Substituting (51) into the optimality condition of the representative worker, we obtain the formula for the limiting labor income tax

$$
\tau^{n}=\frac{\varrho_{4}-\varrho_{3} F_{n}}{F_{n}} \frac{\mu}{\theta-\mu \varrho_{3}} .
$$

The proof is completed. 


\section{References}

[1] Atkinson, A.B., Stiglitz, J.S., 1980. Lectures on Public Economics. New York: McGrawHill.

[2] Bakshi, Gurdip, and Zhiwu, Chen. 1996. The Spirit of Capitalism and Stock-Market Prices. American Economic Review 86, 133-157.

[3] Boileau, Martin, and Rebecca, Braeu. 2007. The Spirit of Capitalism, Asset Returns, and the Business Cycle. Macroeconomic Dynamics 11, 214-230.

[4] Chamley, Christophe, 1986. Optimal Taxation of Capital Income in General Equilibrium with Infinite Lives. Econometrica 80(3), 607-22.

[5] Cole, Harold, George, Mailath, and Andrew, Postlewaite. 1992. Social Norms, Saving Behavior and Growth. Journal of Political Economy 100, 1092-1125.

[6] Doepke, Matthias, and Fabrizio, Zilibotti. 2008. Occupational Choice and the Spirit of Capitalism. Quarterly Journal of Economics 123(2), 747-793.

[7] Karnizova, Lilia, 2010. The Spirit of Capitalism and Expectation-Driven Business Cycles. Journal of Monetary Economics 57, 739-752.

[8] Kurz, Mordecai, 1968. Optimal Economic Growth and Wealth Effects. International Economic Review 9, 348-357.

[9] Kydland, F.E., E. Prescott, 1977. Rules Rather than Discretion: The Inconsistency of Optimal Plans. Journal of Political Economy 85, 473-491.

[10] Judd, Kenneth, 1985. Redistributive Taxation in a Simple Perfect Foresight Model. Journal of Public Economics 28(1), 59-83.

[11] Lucas, R.E., Stokey, N., 1983. Optimal fiscal and monetary policy in an economy without capital, Journal of Monetary Economics 12, 55-9 3.

[12] Luo, Yulei, and Eric, Young. 2009. The Wealth Distribution and the Demand for Status. Macroeconomic Dynamics 13, 1-30.

[13] Smith, William, 2001. How Does the Spirit of Capitalism Affect Stock Market Prices? Review of Financial Studies 14, 1215-1232.

[14] Xie, Danyang, 1997. On Time Inconsistency: A Technical Issue in Stackelberg Differential Games. Journal of Economic Theory 76, 412-430.

[15] Zou, Heng-fu, 1994. The Spirit of Capitalism and Long-Run Growth. European Journal of Political Economy 10, 279-93.

[16] Zou, Heng-fu, 1995. The Spirit of Capitalism and Savings Behavior. Journal of Economic Behaviro and Organization 28, 131-43. 